(2) Open Access Full Text Article

\title{
Long-term administration of high doses of transdermal buprenorphine in cancer patients with severe neuropathic pain
}

This article was published in the following Dove Press journal:

OncoTargets and Therapy

4 December 2015

Number of times this article has been viewed

\section{Wojciech Leppert \\ Grzegorz Kowalski}

Chair and Department of Palliative Medicine, Poznan University of

Medical Sciences, Poznan, Poland
Correspondence: Wojciech Leppert Chair and Department of Palliative Medicine, Poznan University of Medical Sciences, 25A Osiedle Rusa 55, Poznan 61 245, Poland

Tel/fax +48 6I 8738303

Email wojciechleppert@wp.pl
Background: Buprenorphine is often administered by the transdermal route (transdermal buprenorphine $[\mathrm{TB}]$ ) in cancer patients with severe neuropathic pain. However, high doses of TB of $140 \mu \mathrm{g} / \mathrm{h}$ are rarely used.

Patients and methods: Three cancer patients with severe neuropathic Numeric Rating Scale (NRS) pain scores of 8-10 who were successfully treated with high doses of TB up to $140 \mu \mathrm{g} / \mathrm{h}$ along with other opioids and adjuvant analgesics.

Results: TB was administered for a long period of follow-up ( 9 months to 4 years, including 34-261 days of treatment with the dose of $140 \mu \mathrm{g} / \mathrm{h}$ ), which allowed achievement of satisfactory analgesia (NRS 3-5) and good treatment tolerance. In all three patients, TB dose was gradually titrated from 35 to $140 \mu \mathrm{g} / \mathrm{h}$, and all patients used morphine at least for some time for breakthrough and background pain management along with adjuvant analgesics. Two patients continued the treatment with TB until the end of life, and one patient is still receiving the treatment.

Conclusion: TB at doses of up to $140 \mu \mathrm{g} / \mathrm{h}$ in cancer patients with severe neuropathic pain seems to be effective and safe in combination with other opioids and with adjuvant analgesics, and may significantly improve patients' quality of life. Clinical studies may explore higher than maximal $140 \mu \mathrm{g} / \mathrm{h}$ TB doses recommended by a manufacturer, and also in combination with other opioids and adjuvant analgesics.

Keywords: adverse effects, analgesia, cancer, neuropathic pain, transdermal buprenorphine, treatment

\section{Introduction}

Buprenorphine is one of the "strong" opioid analgesics often used in the management of cancer patients with moderate-to-severe pain intensity and in other chronic nonmalignant pain syndromes. ${ }^{1,2}$ Buprenorphine is nowadays most commonly administered by the transdermal route in patches (transdermal buprenorphine [TB]), releasing 35 , 52.5 , and $70 \mu \mathrm{g}$ of the drug per hour, which corresponds to daily buprenorphine doses of $0.8,1.2$, and $1.6 \mathrm{mg}$, respectively. Patches are changed every 84-96 hours and have a matrix structure, which allows for convenient drug dosing, usually twice a week (every 84 hours), and allows for a constant release rate of the drug, diminishing the risk associated with release of a larger amount of the drug during patch damage. ${ }^{3}$

Although buprenorphine is classified usually at the third step of the World Health Organization analgesic ladder, it has different features compared to other "strong" opioids. Buprenorphine analgesic efficacy in neuropathic pain is most probably due to the suggested antihyperalgesic effect of the drug. Apart from a partial agonist activity to $\mu$ - and $\delta$-receptors, it displays a weak agonist or antagonist effect on $\kappa$-opioid receptors 
and acts through ORL1 receptors. ${ }^{4}$ Buprenorphine is an opioid recommended for patients with renal impairment and during dialysis. ${ }^{5,6}$ In contrast to morphine, buprenorphine does not display a significant immunosuppressant effect. ${ }^{7,8}$ Buprenorphine analgesia is independent of P-glycoprotein expression, a protein responsible for drug transport through the blood-brain barrier, which may influence morphine analgesia. ${ }^{9}$

TB treatment in opioid- or "strong" opioid-naïve patients is normally started with doses of 17.5 or $35 \mu \mathrm{g} / \mathrm{h}$ gradually titrated to satisfactory analgesia and acceptable adverse-effect intensity. As lower TB-patch strengths $(5,10$, or $15 \mu \mathrm{g} / \mathrm{h})$ designed for 7 days' treatment are unavailable in Poland, the lowest patch dose available is $35 \mu \mathrm{g} / \mathrm{h}$. Therefore, in some patients that require lower starting TB doses, the $35 \mu \mathrm{g} / \mathrm{h}$ patch is cut to half, containing a dose of TB equal to $\sim 17.5 \mu \mathrm{g} / \mathrm{h}$.

The aim of the study was to assess analgesia and adverse effects of high doses of buprenorphine used for the management of three cancer patients with severe neuropathic pain, with a focus on patients' safety. Patient 1 agreed to the publication of his disease trajectory without unveiling his personal data, the other two patients died, so it was impossible to obtain their agreement for this publication. The Local Bioethics Committee of the Poznan University of Medical Sciences approved the study protocol.

\section{Case I}

A 41-year-old patient diagnosed with chondrosarcoma located in the sacral bone after numerous surgical interventions and radical radiotherapy had been experiencing pain since spring 2006 in the right sacral region radiating to the right lower extremity, of neuropathic characteristics. In September 2006, magnetic resonance imaging revealed a tumor of the lumbosacral region; the patient underwent several surgical interventions and radical radiotherapy in 2010, but a recurrence of the tumor was found. In December 2010, a colostomy was done, followed by a total tumor resection with sacropelvic stabilization, skin, and subcutaneous tissue plasticity with transplantation of skin-muscle flaps to cover the defect in January 2011. Although local complication occurred and the patient stayed in bed due to lower-extremities paralysis, investigations did not reveal any signs of the tumor relapse.

Pain in the lumbar spine radiating to lower extremities of neuropathic characteristics significantly intensified at the end of 2008. In February 2009, pain became severe (Numeric Rating Scale [NRS] 8), the patient was prescribed transdermal fentanyl $25 \mu \mathrm{g} / \mathrm{h}$ every 72 hours, controlledrelease morphine titrated to a dose of $100 \mathrm{mg}$ twice daily, immediate-release morphine $15-30 \mathrm{mg}$ in case of breakthrough pain, venlafaxine $75 \mathrm{mg}$ once daily, carbamazepine $150 \mathrm{mg}$ twice daily, and lactulose $7.5 \mathrm{~g}$ three times daily, with good analgesia (NRS 4-5). Until April 2011, when the patient returned home, carbamazepine was substituted with pregabalin at a dose of $75 \mathrm{mg}$ twice daily. At this time, as the patient was tolerating morphine poorly due to significant drowsiness and difficulties in concentrating, the regular controlled-release morphine dose was gradually decreased and finally completely withdrawn with a dose of 10-20 mg of immediate-release morphine prescribed for breakthrough pain and an addition of a regular paracetamol of $500 \mathrm{mg}$ administered three times daily.

In September 2011, pain intensified (NRS 6) and the patient asked about changing pain medications. A fentanyl patch $25 \mu \mathrm{g} / \mathrm{h}$ was switched to TB at a dose of $35 \mu \mathrm{g} / \mathrm{h}$ twice a week. Analgesia improved (NRS 4), with satisfactory tolerance of the treatment, and it was possible to stop paracetamol administration. However, in February 2012, due to an increase in pain intensity (NRS 5), the dose of buprenorphine patch was increased to $52.5 \mu \mathrm{g} / \mathrm{h}$, and again satisfactory analgesia was achieved (NRS 3). In November 2012, again pain intensified (NRS 6), the dose of buprenorphine was increased to $70 \mu \mathrm{g} / \mathrm{h}$, and again satisfactory analgesia was achieved (NRS 3).

In June 2013, the buprenorphine dose was increased to 105 $\mu \mathrm{g} / \mathrm{h}$ and in September 2014 to $140 \mu \mathrm{g} / \mathrm{h}$, and again satisfactory analgesia was achieved (NRS 3). In June 2014, the dose of pregabalin was increased to $150 \mathrm{mg}$ twice daily while maintaining the venlafaxine dose ( $75 \mathrm{mg}$ once daily). Breakthrough pain episodes were controlled with fentanyl buccal tablets of a dose of $200 \mu \mathrm{g}$ once or twice daily. The patient continued the treatment with satisfactory analgesia (NRS 4) without significant adverse effects; occasionally, lactulose $20 \mathrm{~mL}$ was taken to render a bowel movement. However, as the pain intensified, the patient started controlled-release morphine at a dose of $10 \mathrm{mg}$ in March 2015, increased subsequently to 20 mg twice daily, which provided satisfactory analgesia together with TB and adjuvant analgesics (Figure 1).

\section{Case 2}

A 64-year-old patient was diagnosed with a thyroid follicular carcinoma and bone metastases (lumbar spine, right scapula, and both femur bones). In 2000, the patient underwent surgical intervention: a resection of the left thyroid lobe and a subtotal strumectomy was conducted, with histopathology claimed to be benign. However, in 2003, bone metastases were found in the thoracic and lumbar spine that originated from a follicular thyroid cancer formerly misdiagnosed as a benign tumor. 


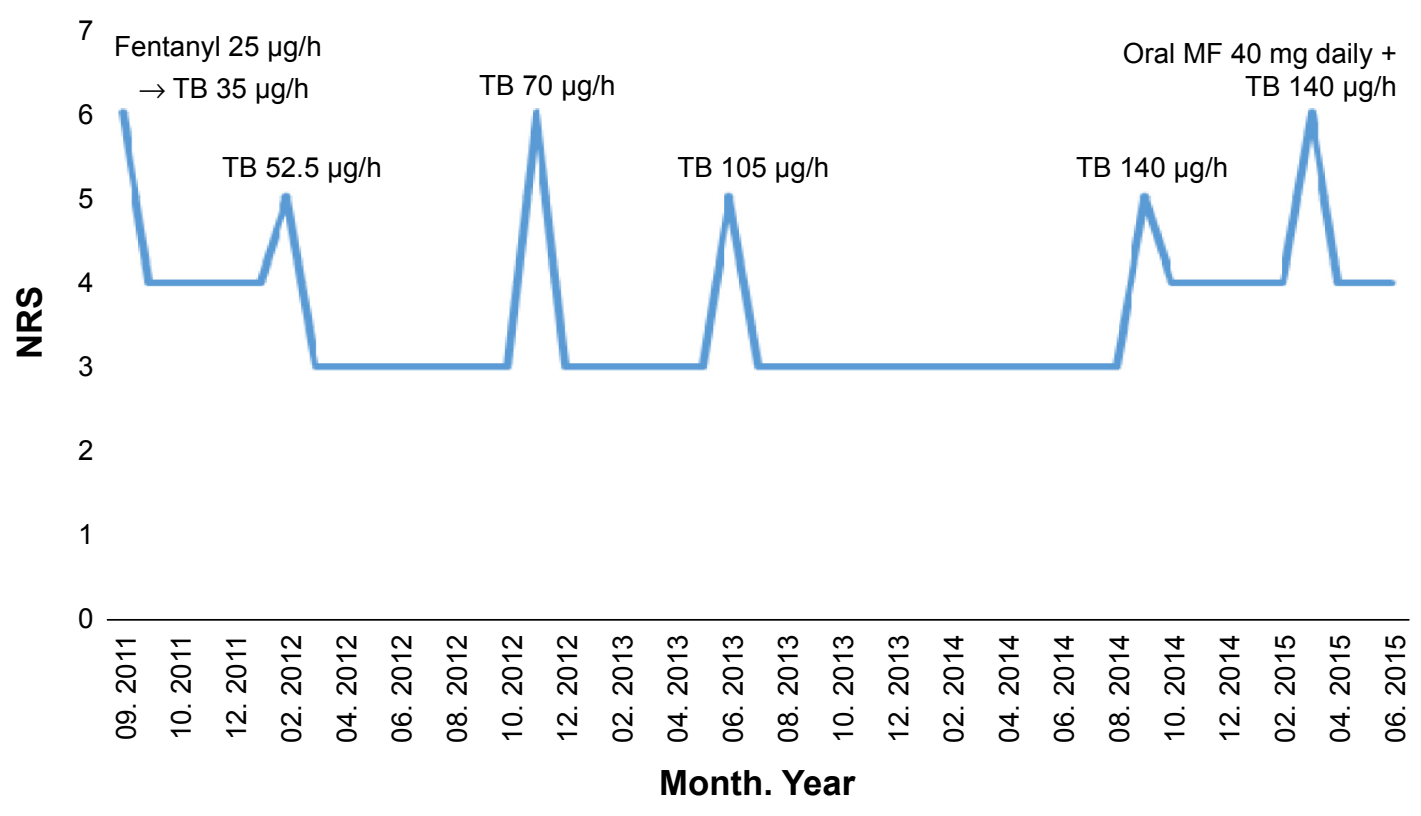

Figure I Pain intensity and TB doses in a patient diagnosed with chondrosarcoma of the sacral bone.

Abbreviations: NRS, Numeric Rating Scale (0 - no pain, 10 - the most severe pain intensity); TB, transdermal buprenorphine; MF, morphine.

Palliative radiotherapy was administered for spine metastases in 2003 and 2004, and a vertebroplasty was performed in 2004 of Th9 and L4. The patient started treatment with radioactive iodine, which was repeated once a year in the endocrinology department at our university.

In 2006, the patient was referred to our Outpatient Palliative Medicine Clinic, due to periodic mild pain in the lumbar spine region, which did not require regular analgesic treatment; the patient received orally one of three drugs as needed: paracetamol $500 \mathrm{mg}$, ketoprofen $100 \mathrm{mg}$, or tramadol 25-50 mg in drops with good analgesia (NRS 1-2). The patient was also treated with a regular (every 28 days) pamidronate intravenous infusion at a dose of $60 \mathrm{mg}$ that was very well tolerated.

In December 2012, headache and nausea appeared, and brain metastasis was diagnosed. In January 2013, neurosurgery was conducted, followed by whole-brain radiotherapy. However, in February 2013, the patient's general condition significantly deteriorated, and the patient qualified for a palliative home-care program.

In February 2013, due to intense bone and neuropathic pain (NRS 8-10) located in the lumbar spine radiating to the lower extremities and in the right scapula (pathological fracture), TB was started at a dose of $35 \mu \mathrm{g} / \mathrm{h}$, with initial good response (NRS 4). However, due to increased pain intensity during the next 3 months, the dose of buprenorphine was gradually increased $(52.5,70,105 \mu \mathrm{g} / \mathrm{h})$ up to a final dose of $140 \mu \mathrm{g} / \mathrm{h}$. At the beginning of buprenorphine treatment, immediate-release morphine at a dose of $20 \mathrm{mg}$ as needed was administered orally, followed by regular administration of $20 \mathrm{mg}$ two to three times daily. For breakthrough pain episodes, buccal fentanyl tablets were administered at a dose of $100 \mu \mathrm{g}$, with good analgesic effects. Pregabalin at a dose of $75 \mathrm{mg}$ twice daily and amitriptyline $25 \mathrm{mg}$ once daily were added for pain, the latter also for mood improvement, which had significantly deteriorated.

In June 2013, the patient underwent a course of palliative radiotherapy for the lumbar spine region. After 1 month, it was possible to decrease the regularly administered immediaterelease morphine to $20 \mathrm{mg}$ once daily while maintaining the buprenorphine dose and adjuvants. In September 2013, the dose of buprenorphine was reduced to $105 \mu \mathrm{g} / \mathrm{h}$ and immediate-release morphine was withdrawn. Treatment with buprenorphine was continued at a dose of $70 \mu \mathrm{g} / \mathrm{h}$ at the end of 2013 (Figure 2).

In March 2014, the general condition of the patient deteriorated, with lack of appetite and cognitive impairment. Dexamethasone at a dose of $8 \mathrm{mg}$ once daily intravenously was started, with an improvement in general condition and less cognitive impairment. However, during changing the patient's position in bed, a pathological fracture of the left femur appeared. The patient was admitted to our Palliative Care Unit. Due to their severe general condition, the patient was treated conservatively: apart from buprenorphine at a dose of $70 \mu \mathrm{g} / \mathrm{h}$ in the last days of life, the patient received morphine intravenously at a dose of $30 \mathrm{mg}$ per day. The patient died peacefully after a few days. 


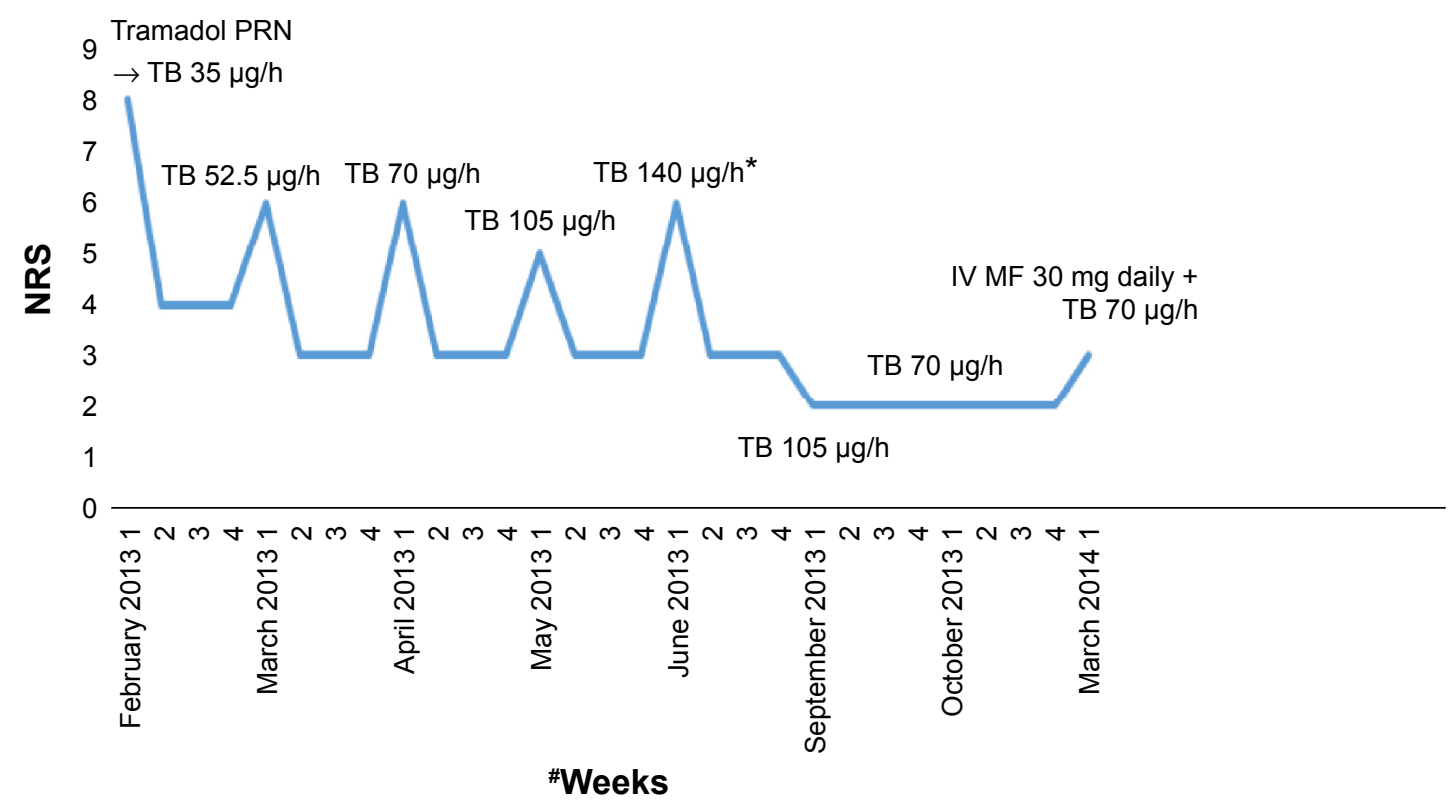

Figure 2 Pain intensity and TB doses in a patient diagnosed with thyroid carcinoma and bone metastases.

Notes: *Palliative radiotherapy for lumbar spine metastases. ${ }^{\sharp}$ I, 2, 3, and 4 refer to the weeks of each month listed.

Abbreviations: NRS, Numeric Rating Scale (0 - no pain, 10 - the most severe pain intensity); TB, transdermal buprenorphine; MF, morphine; IV, intravenous; PRN, pro re nata (as needed).

\section{Case 3}

A 67-year-old patient diagnosed with neuropathic pain in the course of an adenocarcinoma of the rectum with an infiltration of sacral bone was referred to our Outpatient Palliative Medicine Clinic due to severe pain (NRS 10) of the sacral region radiating to lower extremities.

The tumor was found during a colonoscopy in 2011. At the end of 2011 and at the beginning of 2012, radiochemotherapy was introduced (50 Gy/T with 5-fluorouracyl and leucovorin, respectively). In April 2012, a surgical intervention (abdominal-perineal amputation of the rectum) and cholecystectomy due to gallbladder stones were conducted. In August 2012, a positron-emission tomography-computed tomography scan was conducted, and a tumor in the presacral region was found. The patient was treated with FOLFOX (folinic acid, fluorouracil, and oxaliplatin) chemotherapy between September and December 2012. In August 2013, a computed tomography scan unveiled a progression: a bigger infiltration in the presacral region, which penetrated by the nerves through the sacral foramina (left S2 and right S4), and a dissemination to the peritoneum.

The same month, the patient was referred to our homecare program. The patient complained of intense pain (NRS 8) in the sacral region radiating to the left lower extremity (thigh, shin, and foot), intensifying on movement (NRS 9) and weakness, loss of appetite, and nausea. The dose of buprenorphine was increased from 35 to $52.5 \mu \mathrm{g} / \mathrm{h}$, and pregabalin $75 \mathrm{mg}$ twice daily was started. Immediate-release morphine was initially prescribed for breakthrough-pain episodes at a dose of $20 \mathrm{mg}$, and after 2 weeks this dose was regularly administered twice daily with dexamethasone $1 \mathrm{mg}$ with a proton-pump inhibitor. In September, the dose of buprenorphine was increased to $70 \mu \mathrm{g} / \mathrm{h}$.

In December 2013, due to more intense pain, the dose of immediate-release morphine was increased to $3 \times 20 \mathrm{mg}$ and dexamethasone to $2 \times 2 \mathrm{mg}$ with a proton-pump inhibitor. In January 2014, the dose of buprenorphine was increased to $105 \mu \mathrm{g} / \mathrm{h}$, and in February to $140 \mu \mathrm{g} / \mathrm{h}$ with an addition of a controlled-release morphine at a dose of $2 \times 30 \mathrm{mg}$. In March 2014, after a fall at home, a pertrochanteric fracture of the left femur bone was diagnosed, which was treated by surgery (reposition and conjunction). The patient returned home and continued the same treatment, although she was unable to walk and remained in bed.

At the beginning of May 2014, a significant deterioration in general condition was observed; pain had intensified and there was limited contact with the patient. Dexamethasone was started at a dose of $1 \times 8 \mathrm{mg}$ and morphine $10 \mathrm{mg}$ every 4 hours (both drugs administered subcutaneously); after 5 days, due to more intense pain, a continuous morphine infusion was instituted (100 mg per day) while continuing buprenorphine treatment at the same dose, achieving good analgesia (Figure 3). After a few days of treatment, the patient died peacefully at home in the presence of the family. 


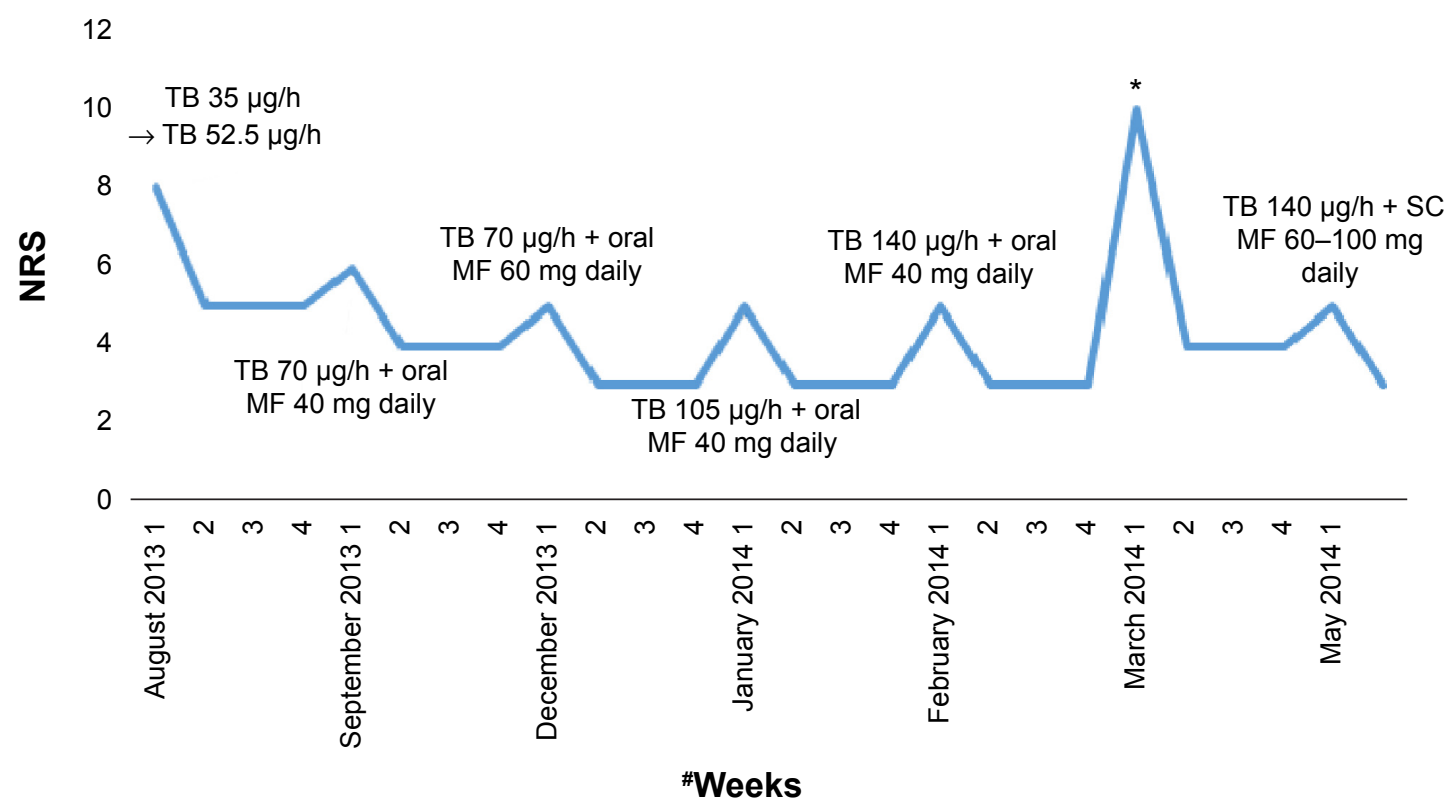

Figure 3 Pain intensity and TB doses in a patient diagnosed with rectal carcinoma and sacral bone infiltration.

Notes: *Pathological fracture of the left femur bone; surgery and a stay in hospital until May 20I4. ${ }^{\# I, ~ 2, ~ 3, ~ a n d ~} 4$ refer to the weeks of each month listed. Abbreviations: NRS, Numeric Rating Scale ( 0 - no pain, 10 - the most severe pain intensity); TB, transdermal buprenorphine; MF, morphine; SC, subcutaneous.

\section{Discussion}

In all three patients for a long period of follow-up (range: 34-261 days), satisfactory analgesia (NRS 3-5) was achieved during high-dose $(140 \mu \mathrm{g} / \mathrm{h}) \mathrm{TB}$ administration. Moreover, treatment with TB lasted 9 months, 14 months, and nearly 4 years in patients 3,2 , and 1 , respectively. In the second and third patients, treatment with TB was continued until the end of life. In the first patient, treatment with TB is being continued with concurrent use of adjuvant analgesics pregabalin, venlafaxine, and buccal fentanyl tablets - used for the management of breakthrough-pain episodes and a regular administration of a small morphine dose. During the treatment with TB, no serious adverse events were observed in any of the patients depicted, which would have caused treatment cessation, and buprenorphine patches were very well tolerated in all three patients. As an analgesic effect was beneficial without significant adverse effects during the whole period of TB administration in all three patients, our observations suggest that the treatment of severe neuropathic pain in cancer patients with TB is not only effective but also safe for a long period, and also with high doses of TB up to $140 \mu \mathrm{g} / \mathrm{h}$.

All three patients used regular morphine doses concurrently with TB at least for some time. In the first patient, morphine was administered both regularly and as needed. Later breakthrough pain was more effectively controlled in this patient by buccal fentanyl tablets that provided faster pain relief compared to oral morphine. In the second patient, morphine was initially prescribed for breakthrough-pain episodes and then regularly administered. However, palliative radiotherapy for spine metastases allowed a complete cessation of morphine and a reduction of TB dose. Similarly, in the third patient, immediate-release morphine was initially used for the management of breakthrough-pain episodes only, and later, due to an increase in pain intensity, morphine was administered regularly as immediate-release and then as controlled-release formulations twice daily together with dexamethasone; subsequently, morphine was administered by a subcutaneous route, due to a significant deterioration in general condition and swallowing difficulties. These observations suggest a possible safe combination of TB in doses of up to $140 \mu \mathrm{g} / \mathrm{h}$ with not only opioids administered for breakthrough-pain episodes but also with regularly administered morphine and adjuvant analgesics, such as pregabalin and dexamethasone.

Experimental and clinical data suggest analgesic efficacy of buprenorphine in patients with a neuropathic pain component. ${ }^{4,10}$ However, it is not quite clear which mechanism is responsible for these effects, which may be associated with an action through $\mu$-opioid receptors together with activation of ORL1 receptors at the spinal level and possibly through an upregulation of $\delta$ - and $\kappa$-opioid receptors. ${ }^{1{ }^{11,12}}$ Moreover, the drug, especially in transdermal formulations, is usually very well tolerated. ${ }^{13,14}$ 
It should be emphasized that the dose of TB has to be titrated based on the level of analgesia and adverse-effect intensity. In most patients with severe pain who were opioidnaïve or unsuccessfully treated with step 2 opioids, such as tramadol, codeine, or dihydrocodeine, a starting dose of TB equal to $35 \mu \mathrm{g} / \mathrm{h}$ is safe and effective, although the dose may need to be increased in cases of insufficient analgesia, titrated up to $52.5,70,105$, and $140 \mu \mathrm{g} / \mathrm{h}$, if necessary. However, in some opioid-naïve patients, such as older populations, patients with cachexia, and those with abnormal liver and renal function, a lower starting dose may be more appropriate. In Poland, a patch with a lower dose than $35 \mu \mathrm{g} / \mathrm{h}$ is unavailable; therefore, it is common practice that the 35 $\mu \mathrm{g} / \mathrm{h}$ patch is cut in half, containing a dose of TB of approximately $17.5 \mu \mathrm{g} / \mathrm{h}$. This approach seems to be acceptable, as it should not affect the release rate of buprenorphine from a patch that has a matrix structure. Some clinicians even use a lower starting dose of TB of $8.75 \mu \mathrm{g} / \mathrm{h}$, which is a quarter of the $35 \mu \mathrm{g} / \mathrm{h}$ patch. However, cutting patches in half or into smaller pieces is not officially listed in the summary of product characteristics. ${ }^{15}$

Although buprenorphine is a partial $\mu$-opioid-receptor agonist in the therapeutic dose range of up to $140 \mu \mathrm{g} / \mathrm{h}$ (3.2 mg per 24 hours), this compound displays similar activity to typical pure opioid-receptor agonists, and the "ceiling" effect of analgesia is suggested to appear at a daily dose of $15 \mathrm{mg}$, which is much higher than those used in clinical practice. ${ }^{16,17}$ TB may be safely combined with other opioids administered for breakthrough-pain episodes (morphine, fentanyl nasal spray, or buccal tablets). ${ }^{18-20} \mathrm{~TB}$ doses as high as $175 \mu \mathrm{g} / \mathrm{h}$ and $210 \mu \mathrm{g} / \mathrm{h}$ were successfully used in case 2 and 4 cancer patients, respectively. ${ }^{21-24}$ It may be hypothesized that a combination of buprenorphine with other opioids may provide superadditive effects, due to a different mode of G-protein activation compared to morphine. ${ }^{25}$ However, this hypothesis should be checked in experimental and clinical studies. Interestingly, in our experience, TB is coadministered with other opioids, such as morphine and methadone, as a regular treatment of background pain. ${ }^{26}$ TB may be a useful analgesic for treatment of patients with chronic noncancer- and cancer-related pain. ${ }^{27-30}$

\section{Conclusion}

In spite of limitations typical for case series, our clinical observations suggest the possibility of a safe and effective administration of TB in high doses of up to $140 \mu \mathrm{g} / \mathrm{h}$ in cancer patients with severe neuropathic pain, and also in combination with other opioids and with adjuvant analgesics that may significantly improve patients' quality of life. Clinical studies may explore doses higher than that currently recommended by the summary of product characteristics maximal TB dose of $140 \mu \mathrm{g} / \mathrm{h}$ alone and in combination with other opioids and adjuvant analgesics.

\section{Disclosure}

The authors report no conflicts of interest in this work.

\section{References}

1. Sittl R. Transdermal buprenorphine in cancer pain and palliative care. Palliat Med. 2006;20 Suppl 1:s25-s30.

2. Sittl R, Griessinger N, Likar R. Analgesic efficacy and tolerability of transdermal buprenorphine in patients with inadequately controlled chronic pain related to cancer and other disorders: a multicenter, randomized, double-blind, placebo-controlled trial. Clin Ther. 2003;25: $150-168$.

3. Kusnik S, Likar R, Sittl R. Transdermal buprenorphine in chronic pain: indications and clinical experience. Expert Rev Clin Pharmacol. 2008;1: 729-736.

4. Christoph T, Kögel B, Schiene K, Méen M, De Vry J, Friderichs E. Broad analgesic profile of buprenorphine in rodent models of acute and chronic pain. Eur J Pharmacol. 2005;507:87-98.

5. Caraceni A, Hanks G, Kaasa S, et al. Use of opioid analgesics in the treatment of cancer pain: evidence-based recommendations from the EAPC. Lancet Oncol. 2012;13:e58-e68.

6. Mordarski S. Efficacy and safety of buprenorphine in patients receiving haemodialysis. J Appl Ther Res. 2009;7:46-51.

7. Davis MP. Buprenorphine in cancer pain. Support Care Cancer. 2005; 13:878-887.

8. Cowan A, Friderichs E, Strasburger W, Raffa RB. Pharmacology of buprenorphine. In: Budd K, Raffa RB, editors. Buprenorphine: The Unique Opioid Analgesic. Stuttgart: Georg Thieme Verlag KG; 2006 : 3-25.

9. Wang J, Cai B, Huang DX, Yang SD, Guo L. Decreased analgesic effect of morphine, but not buprenorphine, in patients with advanced P-glycoprotein ${ }^{+}$cancers. Pharmacol Rep. 2012;64:870-877.

10. Szczudlik A, Dobrogowski J, Wordliczek J, et al. Diagnosis and management of neuropathic pain: review of literature and recommendations of the Polish Association for the Study of Pain and the Polish Neurological Society - part two. Neurol Neurochir Pol. 2014;48:423-435.

11. Koppert W, Ihmsen H, Körber N, et al. Different profiles of buprenorphine induced analgesia and antihyperalgesia in a human pain model. Pain. 2015;118:15-22.

12. Belcheva MM, Barg J, McHale RJ, et al. Differential down- and upregulation of rat brain opioid receptor types and subtypes by buprenorphine. Mol Pharmacol. 1993;44:173-179.

13. Kress HG. Clinical update on the pharmacology, efficacy and safety of transdermal buprenorphine. Eur J Pain. 2009;13:219-230.

14. Griessinger N, Sittl R, Likar R. Transdermal buprenorphine in clinical practice-a post-marketing surveillance study. Curr Med Res Opin. 2005; 21:1147-1156.

15. Transtec ${ }^{\circledR}$ [summary of product characteristics]. Stolberg, Germany: Grünenthal GmbH; 2008.

16. Walsh SL, Preston KL, Stitzer ML, Cone EJ, Bigelow GE. Clinical pharmacology of buprenorphine: ceiling effects at high doses. Clin Pharmacol Ther. 1994;55:569-580.

17. Mercadante S, Ferrera P, Villari P. Is there a ceiling effect of transdermal buprenorphine? Preliminary data in cancer patients. Support Care Cancer. 2007;15:441-444.

18. Kögel B, Christoph T, Strassburger W, Friderichs E. Interaction of $\mu$-opioid receptor agonists and antagonists with the analgesic effects of buprenorphine in mice. Eur J Pain. 2005;9:599-611. 
19. Mercadante S, Villari P, Ferrera P, et al. Safety and effectiveness of intravenous morphine for episodic breakthrough pain in patients receiving transdermal buprenorphine. J Pain Symptom Manage. 2006;32: $175-179$.

20. Zarth R. Comparison of buprenorphine, morphine sulphate and fentanyl citrate as rescue medication for breakthrough pain in cancer patients. J Appl Ther Res. 2008;6:15-20.

21. Barutell C, Camba A, González-Escalada JR, Rodríguez M; the Opioid Group of the Spanish Society for the Study of Pain. High dose transdermal buprenorphine for moderate to severe pain in spanish pain centres - a retrospective multicenter safety and efficacy study. Pain Pract. 2008;8(5):355-361.

22. Mertens PG, Cornelissen P, Menten J. The use of high dosages of transdermal buprenorphine for pain management in palliative cancer patients: a case study. Case Rep Oncol. 2013;6:169-173.

23. Gastmeier K, Freye E. [High-dose buprenorphine for outpatient pain therapy]. Schmerz. 2009;23(2):180-186. German.

24. Clement PMJ, Beuselinck B, Mertens PG, Cornelissen P, Menten J. Pain management in palliative cancer patients: a prospective observational study on the use of high dosages of transdermal buprenorphine. Acta Clin Belg. 2013;68(2):87-91.
25. Bulka A, Kouya PF, Böttiger Y, Svensson JO, Xu XJ, WiesenfeldHallin Z. Comparison of the antinociceptive effects of morphine, methadone, buprenorphine and codeine in two substrains of SpragueDawley rats. Eur J Pharmacol. 2004;492:27-34.

26. Leppert W, Kowalski G. Methadone as an additional opioid for a cancer patient with severe neuropathic and bone pain not responsive to other opioids and adjuvant analgesics. J Palliat Care. 2013;29:119-121.

27. Przeklasa-Muszynska A, Dobrogowski J. Transdermal buprenorphine for the treatment of moderate to severe chronic pain: results from a large multicenter, non-interventional post-marketing study in Poland. Cur Med Res Opin. 2011;27:1109-1117.

28. Schmidt-Hansen M, Bromham N, Taubert M, Arnold S, Hilgart JS. Buprenorphine for treating cancer pain. Cochrane Database Syst Rev. 2015;3:CD009596.

29. Deandrea S, Corli O, Moschetti I, Apolone G. Manging severe cancer pain: the role of transdermal buprenorphine: a systematic review. Therap Clin Risk Manage. 2009;5:707-718.

30. Johnson RE, Fudala PJ, Payne R. Buprenorphine: considerations for pain managment. J Pain Symptom Manage. 2005;29(3):297-326.
OncoTargets and Therapy

\section{Publish your work in this journal}

OncoTargets and Therapy is an international, peer-reviewed, open access journal focusing on the pathological basis of all cancers, potential targets for therapy and treatment protocols employed to improve the management of cancer patients. The journal also focuses on the impact of management programs and new therapeutic agents and protocols on

\section{Dovepress}

patient perspectives such as quality of life, adherence and satisfaction. The manuscript management system is completely online and includes a very quick and fair peer-review system, which is all easy to use. Visit http://www.dovepress.com/testimonials.php to read real quotes from published authors. 